\title{
Synaptic potentiation in the nociceptive amygdala following fear learning in mice
}

\author{
Ayako M Watabe ${ }^{1,2 *}$, Toshitaka Ochiai ${ }^{1,3}$, Masashi Nagase ${ }^{1}$, Yukari Takahashi ${ }^{1}$, Masaru Sato ${ }^{1,4}$ and Fusao Kato ${ }^{1,5}$
}

\begin{abstract}
Background: Pavlovian fear conditioning is a classical form of associative learning, which depends on associative synaptic plasticity in the amygdala. Recent findings suggest that the central amygdala (CeA) plays an active role in the acquisition of fear learning. However, little is known about the synaptic properties of the CeA in fear learning. The capsular part of the central amygdala $(\mathrm{CeC})$ receives direct nociceptive information from the external part of the lateral parabrachial nucleus (IPB), as well as highly processed polymodal signals from the basolateral nucleus of the amygdala (BLA). Therefore, we focused on CeC as a convergence point for polymodal BLA signals and nociceptive IPB signals, and explored the synaptic regulation of these pathways in fear conditioning.

Results: In this study, we show that fear conditioning results in synaptic potentiation in both IPB-CeC and BLA-CeC synapses. This potentiation is dependent on associative fear learning, rather than on nociceptive or sensory experience, or fear memory retrieval. The synaptic weight of the IPB-CeC and BLA-CeC pathways is correlated in fear-conditioned mice, suggesting that fear learning may induce activity-dependent heterosynaptic interactions between IPB-CeC and BLA-CeC pathways. This synaptic potentiation is associated with both postsynaptic and presynaptic changes in the IPB-CeC and BLA-CeC synapses.

Conclusions: These results indicate that the $\mathrm{CeC}$ may provide an important locus of Pavlovian association, integrating direct nociceptive signals with polymodal sensory signals. In addition to the well-established plasticity of the lateral amygdala, the multi-step nature of this association system contributes to the highly orchestrated tuning of fear learning.
\end{abstract}

Keywords: Central amygdala, Fear conditioning, Synapse, Plasticity, Potentiation, Mouse, Nociception

\section{Background}

The amygdala plays a key role in fear learning by attaching emotional value to various types of sensory input $[1,2]$. In Pavlovian fear conditioning, a previously emotionally neutral conditioned stimulus (CS) acquires the ability to elicit defensive responses when it is presented in conjunction with an aversive unconditioned stimulus (US). While this associative learning has been considered to occur within the lateral nucleus of the amygdala (LA), growing evidence suggests that the central nucleus of the amygdala (CeA), which was previously considered to function as a passive relay to

\footnotetext{
* Correspondence: awatabe@jikei.ac.jp

${ }^{1}$ Department of Neuroscience, Jikei University School of Medicine, Tokyo 105-8461, Japan

${ }^{2}$ Precursory Research for Embryonic Science and Technology (PRESTO), Japan Science and Technology Agency, Kawaguchi, Saitama 332-0012, Japan Full list of author information is available at the end of the article
}

downstream targets that mediate fear responses, also plays an active role in the acquisition of fear learning $[3,4]$. These findings suggest that both the LA and CeA play crucial roles in associating the US with the CS, and that neuronal plasticity in the LA and CeA may regulate associative fear learning in a cooperative manner.

CeA neurons are predominantly GABAergic inhibitory neurons, and can be divided into at least three distinct subnuclei; lateral, capsular and medial $(\mathrm{CeL}, \mathrm{CeC}$ and CeM) [5-8]. Recent reports suggest that the CeL and/or the $\mathrm{CeC}$ tonically inhibit $\mathrm{CeM}$, and fear learning induces disinhibition of this microcircuit [9-11]. However, while these studies have clearly demonstrated changes in CeL/ $\mathrm{CeC}$ activity during and after the acquisition of fear learning using unit recording in vivo, little is known about how these changes are regulated synaptically.

The $\mathrm{CeC}$ has been termed the nociceptive amygdala. This area receives major input directly from the external 
part of the pontine lateral parabrachial nucleus (IPB), which is a major target of nociceptive superficial layers of the dorsal horn [12-16]. The $\mathrm{CeC}$ also receives excitatory input from the basolateral nucleus of the amygdala (BLA), which transmits polymodal sensory information, including nociception, from thalamic and cortical regions [17-21]. Together, these findings suggest that the $\mathrm{CeC}$ may also be an important locus of CS-US association by integrating BLA and IPB signals.

Despite recent demonstration of nociception-induced plasticity at BLA-CeC and IPB-CeC synapses [14,22-25] and of an N-methyl-D-aspartate (NMDA) receptor-independent presynaptic form of long-term potentiation (LTP) at lPBCeL synapses [26], it is still unclear how the $\mathrm{CeC}$ is involved in fear learning, which uses nociceptive inputs as US.

Here we found that the synaptic weights of both IPB$\mathrm{CeC}$ and BLA-CeC pathways were increased after fear learning in an associative manner, and were mediated by both presynaptic and postsynaptic mechanisms. These results suggest that the $\mathrm{CeC}$ may constitute another locus of CS-US association, in addition to the LA, in fear learning.

\section{Results}

\section{Synaptic potentiation at IPB-CeC and BLA-CeC synapses} after fear learning

Previous studies have reported that $\mathrm{IPB}-\mathrm{CeC}$ synapses and BLA-CeC synapses are morphologically distinct. Most IPB-CeC synapses are asymmetric shaft synapses formed on proximal dendrites, and are typically large in size. In contrast, most BLA-CeC synapses are spinal synapses on more distal dendrites, and tend to be smaller in size [27]. Thus, it is possible that information from the $\mathrm{PBB}$ and BLA pathways can be integrated by $\mathrm{CeC}$ neurons in a cooperative manner during the fear learning process. To examine this possibility, we first compared the input-output relationship in both IPB$\mathrm{CeC}$ and BLA-CeC synapses in brain slices obtained from the following five groups of mice: naive group, fear-conditioned (FC) group, FC alone group, CS alone group, and unpaired group (Figure 1A). We examined the behavior of these mice (Figure 1B) and then analyzed the effects of the different procedures on evoked EPSCs recorded at a holding potential of $-60 \mathrm{mV}$ in the presence of $100 \mu \mathrm{M}$ picrotoxin at both $\mathrm{PBB}-\mathrm{CeC}$ synapses and BLA-CeC synapses in vitro (Figure $1 \mathrm{C}, \mathrm{D}$ and 2 ). Fear conditioning consisted of nine pairings of tones as CS and foot shocks as US in a conditioning chamber. The mice then completed a retrieval test $24 \mathrm{~h}$ later in a retrieval chamber which has distinct feature from a conditioning chamber, and were subjected for slice preparation approximately $15 \mathrm{~min}$ after the end of the retrieval test (Figure 1A). Mice in the $\mathrm{FC}$ alone group were subjected to fear conditioning but were not given the retrieval test session the next day. Mice in the CS alone group were not given conditioning, and only received the $\mathrm{CS}$, and were then subjected to testing $24 \mathrm{~h}$ later. Mice in the unpaired group were given US immediately after getting into the chamber, but the CS was given much later, so that no CS-US association formed (Figure 1A). During the retrieval test, the mice in the FC group showed robust freezing behavior $(65.0 \pm 2.1 \%)$ during the first 30 -s period of CS exposure (pre-CS; $12.5 \pm 2.0 \%, \mathrm{n}=16, p<0.001$ ), while the mice in the CS alone and unpaired groups showed a much lower level of freezing behavior during the first 30-s period of CS exposure (CS alone group: $11.66 \pm 2.35 \%$ and $2.25 \pm 0.53 \%, \mathrm{n}=5, p=0.015$; unpaired group: $10.66 \pm 4.20$ and $6.58 \pm 1.71 \%, \mathrm{n}=5, p=0.408$; for the first $30 \mathrm{~s}$ of CS and pre-CS, respectively; Figure 1B). We then prepared coronal brain slices containing the amygdala (Figure 1C, D) approximately 15 min after the end of retrieval for the FC, CS alone and unpaired group, $24 \mathrm{~h}$ after conditioning for the $\mathrm{FC}$ alone group, and after handling-habituated only for the naive group (Figure 1A). Significant intergroup differences in evoked excitatory postsynaptic currents (EPSCs) at the $\mathrm{IPB}-\mathrm{CeC}$ and BLA$\mathrm{CeC}$ synapses were found (Figure 2).

Dunnett's post hoc test following one-way ANOVA to compare multiple groups with a control naive group revealed that the EPSCs at the IPB-CeC synapse had a significantly larger amplitude in FC and FC alone mice, but not in the CS alone or unpaired mice compared with naive mice $\left(100 \mu \mathrm{A}\right.$ : [ANOVA] $\mathrm{F}_{4,102}=1.933, p=0.111$, naive vs. FC, $p=0.034 ; 200 \mu \mathrm{A}: \mathrm{F}_{4,102}=4.247, p=0.003$, naive vs. FC, $p=0.001 ; 300 \mu \mathrm{A}: \mathrm{F}_{4,83}=3.466, p=0.011$, naive vs. FC, $p=0.012 ; 400 \mu \mathrm{A}: \mathrm{F}_{4}, 98=4.181, p=0.004$, naive vs. FC, $p=0.002$, naive vs. FC alone, $p=0.042 ; 500 \mu \mathrm{A}$ : $\mathrm{F}_{4,77}=2.942, p=0.026$, naive vs. $\mathrm{FC}, p=0.018$, naive vs. FC alone, $p=0.042$ ) (Figure 2A2, A3). These results suggest that basal synaptic transmission at IPB-CeC synapses is enhanced after fear learning. In addition, we found that evoked EPSCs at BLA-CeC synapses were also significantly enhanced in a fear learning-dependent manner (Figure 2B). The amplitude of EPSCs at BLA-CeC synapses were also greatly enhanced in FC and FC alone mice, but not in CS alone or unpaired mice compared with naive mice $\left(200 \mu \mathrm{A}\right.$ : [ANOVA] $\mathrm{F}_{4,80}=2.642, p=0.040$, naive vs. $\mathrm{FC}$ alone, $p=0.020 ; 300 \mu \mathrm{A}: \mathrm{F}_{4,98}=3.222, p=0.017 ; 400 \mu \mathrm{A}$ : $\mathrm{F}_{4,98}=4.181, p=0.032$, naive vs. $\mathrm{FC}, p=0.048 ; 500 \mu \mathrm{A}$ : $\mathrm{F}_{4,68}=3.009, p=0.024$, naive vs. $\mathrm{FC}, p=0.033$ ) (Figure 2B2, B3). Passive membrane properties, such as resting membrane potential and input resistance, were indistinguishable between the groups (Em: [ANOVA] $\mathrm{F}_{4,112}=1.441$, $p=0.225$; Ri: $\mathrm{F}_{4,114}=0.707, p=0.589$ ) (Table 1). These results strongly suggest that basal synaptic transmission at both $\mathrm{PB}-\mathrm{CeC}$ and BLA-CeC synapses are enhanced after fear learning. Furthermore, this potentiation is associative, and not primarily dependent on fear retrieval or nociceptive experience per se, but rather on fear learning. 

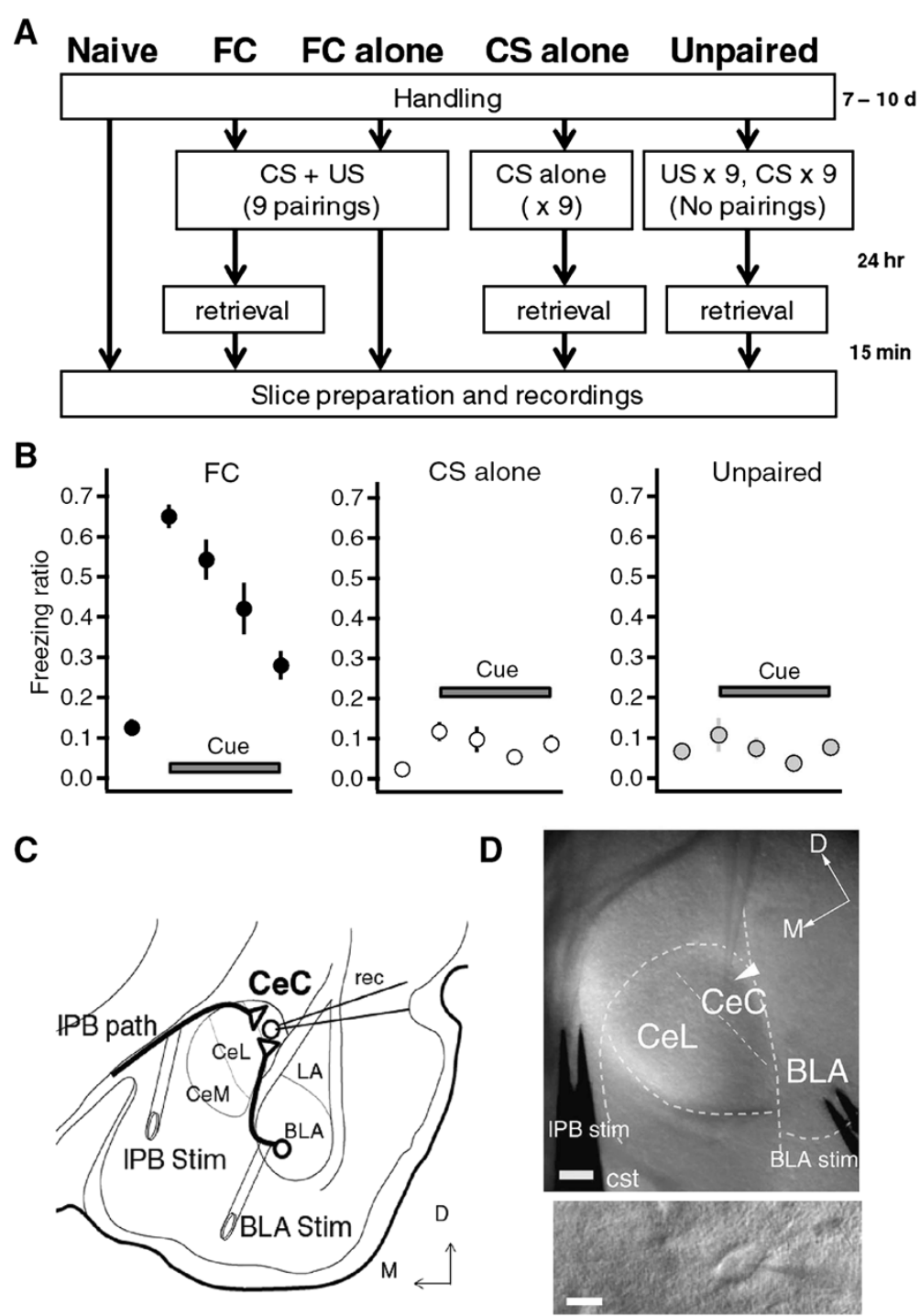

Figure 1 Experimental setup to examine IPB-CeC and BLA-CeC EPSCs following fear learning. A, Experimental schedules for the five different mice groups. FC, fear conditioning; CS, conditioned stimulus; US, unconditioned stimulus. B, Freezing time ratio during retrieval. The first points represent the freezing ratio during the 2 -min baseline period in the chamber, while the $2^{\text {nd }}$ to $5^{\text {th }}$ points corresponds to $1-30 \mathrm{~s}, 31-60 \mathrm{~s}$, 61-90 s and 91-120 s after the onset of the CS presentation. C, Recording configuration for IPB-CeC and BLA-CeC EPSCs. D, Oblique illumination optical images showing electrode placement (tip of a recording electrode indicated with an arrowhead) and CeC cells (bottom). Scale bars are $100 \mu \mathrm{m}$ (top) and $10 \mu \mathrm{m}$ (bottom).

\section{Presynaptic changes following fear learning at IPB-CeC and BLA-CeC synapses}

To explore the mechanisms underlying the synaptic potentiation observed at the $\mathrm{PB}-\mathrm{CeC}$ and $\mathrm{BLA}-\mathrm{CeC}$ synapses, we investigated the possible involvement of presynaptic mechanisms by measuring the paired-pulse ratio (PPR) of EPSCs, a parameter affected by changes in release probability from the presynaptic terminal [28]. We found that the PPR at $\mathrm{PBB}-\mathrm{CeC}$ synapses was significantly decreased in the FC and FC alone groups, but not in the CS alone or unpaired groups, compared with naive mice (PPR: $1.50 \pm 0.07,1.20 \pm 0.05,1.28 \pm 0.05$,
$1.44 \pm 0.08$ and $1.32 \pm 0.08 ; n=28,29,22,15$ and 18 for naive, FC, FC alone, CS alone and unpaired groups, respectively. ANOVA followed by Dunnett's test: $\mathrm{F}_{4,102}=$ 3.906, $p=0.005$, naive vs. FC, $p=0.002$, naive vs. FC alone, $p=0.046$. Figure $3 \mathrm{~A}, \mathrm{~B})$. The PPR at BLA-CeC synapses was also significantly decreased in the FC group compared with the naive group. The FC alone, CS alone and unpaired groups did not display significant differences (PPR: $1.38 \pm 0.07,1.11 \pm 0.07,1.21 \pm 0.05$, $1.31 \pm 0.11$ and $1.23 \pm 0.07 ; \mathrm{n}=22,14,16,12$ and 15 for naive, FC, FC alone, CS alone and unpaired groups, respectively. ANOVA followed by Dunnett's test: $F_{4,76}=$ 


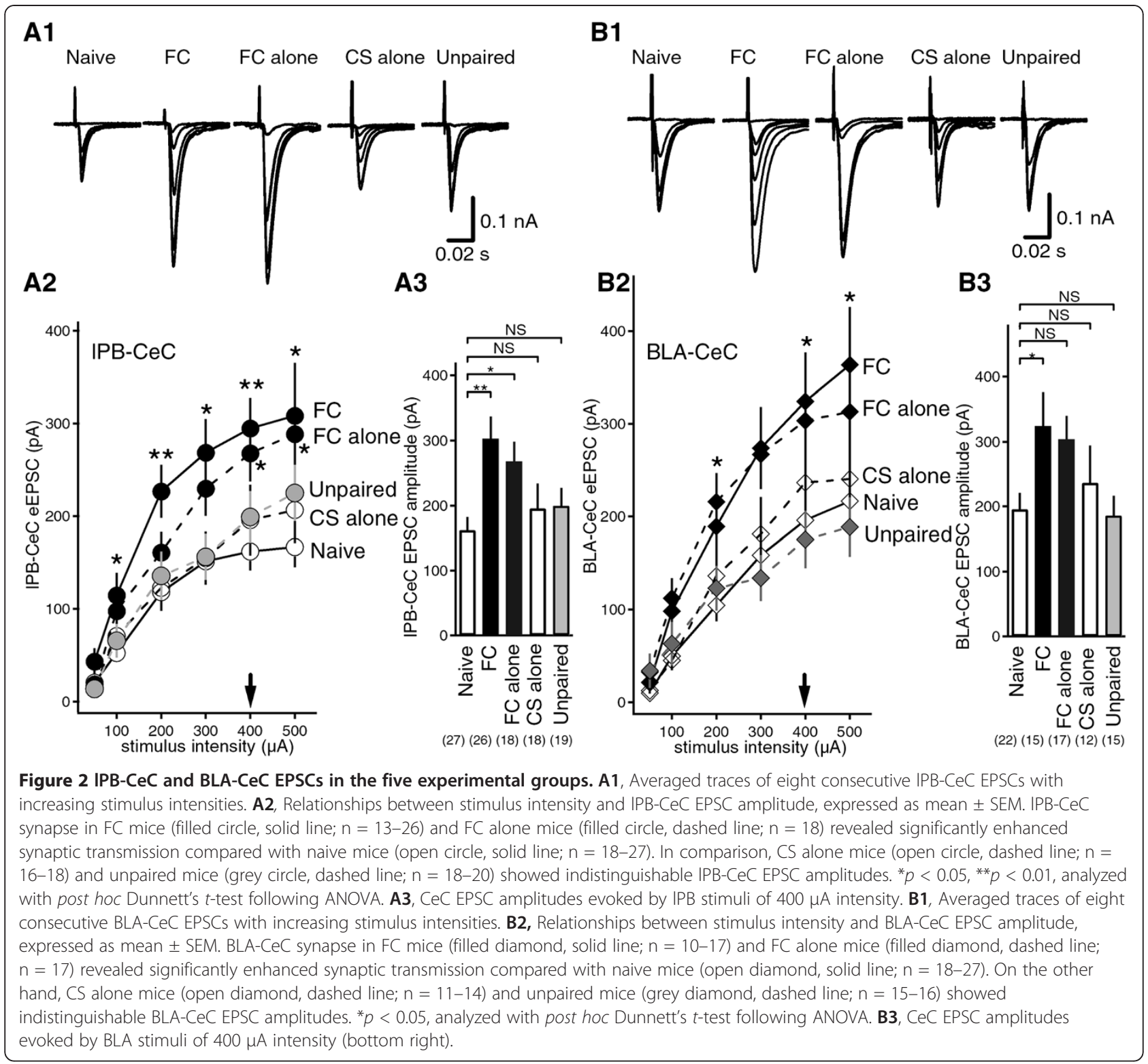

1.992, $p=0.104$, naive vs. FC, $p=0.039$; Figure 3A, C). These results suggest that the release probability from presynaptic terminals was increased in both the $\mathrm{IPB}-\mathrm{CeC}$ and BLA-CeC pathways in fear-conditioned mice, contributing to the synaptic potentiation observed in Figure $2 \mathrm{~A}$ and $\mathrm{B}$.
Postsynaptic mechanisms underlying the potentiation of IPB-CeC and BLA-CeC synapses

Most, if not all, of the $\mathrm{CeC}$ neurons receive excitatory inputs from both the IPB and BLA pathways [25,29]. We therefore examined whether the increase in evoked EPSC amplitude in one of these pathways was associated with a

Table 1 Passive membrane properties of $\mathrm{CeC}$ neurons

\begin{tabular}{lcr}
\hline \multicolumn{1}{c}{ Groups } & Resting membrane potential $(\mathbf{m V})$ & Input resistance $(\mathbf{M \Omega})$ \\
\hline Naive $(n=30)$ & $-62.7 \pm 0.7$ & $191.1 \pm 17.7$ \\
FC $(n=29)$ & $-64.5 \pm 1.0$ & $199.6 \pm 25.2$ \\
FC alone $(n=22)$ & $-62.1 \pm 1.8$ & $223.0 \pm 33.5$ \\
CS alone $(n=18)$ & $-61.2 \pm 1.2$ & $169.9 \pm 15.9$ \\
Unpaired $(n=20)$ & $-61.0 \pm 1.3$ & $218.0 \pm 26.6$ \\
\hline
\end{tabular}




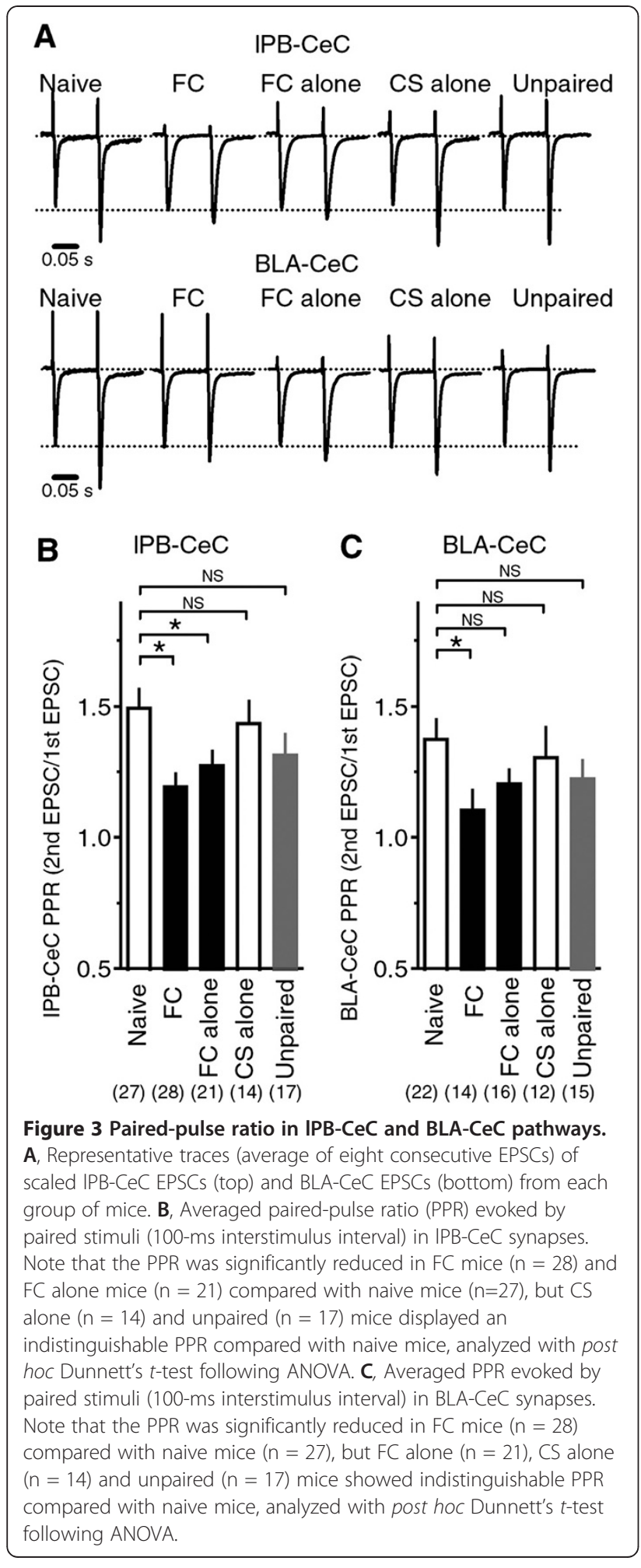

change in the other pathway in individual neurons. To address this, we stimulated the IPB and BLA pathways alternately and compared the amplitude of IPB-CeC EPSCs and BLA-CeC EPSCs recorded with identical stimulus intensities $(400 \mu \mathrm{A}-500 \mu \mathrm{A})$ (Figure $4 \mathrm{~A})$. In naive mice, there was no significant correlation between the $\mathrm{PBB}-\mathrm{CeC}$ EPSCs and BLA-CeC EPSCs recorded in each CeC neuron (Pearson's correlation, $\mathrm{r}=0.055, p=0.762, \mathrm{n}=33$ ). In contrast, there was a significant correlation between the amplitudes of EPSCs in these pathways after fear learning $(\mathrm{r}=0.393, p=0.035, \mathrm{n}=29$; Figure $4 \mathrm{~B})$. While these results suggest some form of heterosynaptic plasticity might coordinate the changes in the two pathways, another possibility is that the electrical stimuli delivered at the two sites activate partially overlapping sets of axons. To rule out this possibility, we performed "cross-pathway PPR experiments", in which the $\mathrm{PB}-\mathrm{CeC}$ pathway was stimulated $50 \mathrm{~ms}$ after the BLA-CeC pathway, and vice versa, in naive male C57BL/6 J mice. Cross-pathway PPR is defined as $\mathrm{EPSC}_{2}$ 2nd BLA of cross-path PPR (IPB-BLA)/EPSC 1 st BLA of singlepath PPR (BLA-BLA) for IPB effect on BLA pathway, and EPSC 2nd IPB of cross-path PPR (BLA-IPB)/EPSC 1 st IPB of single-path PPR (IPB-IPB) for BLA effect on IPB pathway. We found that prior stimulation in one pathway had an almost negligible effect on the EPSC amplitude of the other pathway (for IPB effect on BLA: $0.99 \pm 0.08, n=6$; BLA effect on IPB: $0.99 \pm 0.02, \mathrm{n}=6)$. The conventional PPRs, with 50 -ms interval, were $1.82 \pm 0.11$ and $2.05 \pm 0.12$ for the BLA $(n=6)$ and IPB $(n=6)$ pathways, respectively, in the same cells obtained before and after the cross-pathway PPR experiments. Taken together, the data indicate that fear learning induces potentiation at both IPB and BLA synaptic inputs onto $\mathrm{CeC}$ neurons, and suggest that a type of cooperative postsynaptic interaction occurs between the IPB-CeC and BLA-CeC pathways when their signals are integrated by $\mathrm{CeC}$ neurons.

To further explore postsynaptic mechanisms underlying the synaptic potentiation of the two pathways, we next examined the effects of FC on the ratio of $\mathrm{N}$-methyl-D-aspartate (NMDA) receptor-mediated EPSCs to $\alpha$-amino-3-hydroxy-5-methyl-4-isoxazolepropionic acid (AMPA) receptor-mediated EPSCs at both synaptic inputs. We found that the averaged value of the NMDA/ AMPA ratio tended to increase, but this tendency did not reach statistical significance at either $\mathrm{IPB}-\mathrm{CeC}$ synapses $(29.78 \pm 4.23 \%$ for naive mice and $35.82 \pm$ $3.58 \%$ for FC mice, $\mathrm{n}=17$ and 21, respectively; $p=0.28$; Figure $5 \mathrm{~A}$ ) or BLA-CeC synapses (33.69 $\pm 6.06 \%$ for naive mice and $46.94 \pm 6.54 \%$ for FC mice, $\mathrm{n}=11$ and 10 , respectively; $p=0.15$; Figure $5 \mathrm{~B}$ ). The lack of an effect of fear conditioning on NMDA/AMPA ratios suggests the potentiation of $\mathrm{PB}$ and BLA synapses onto $\mathrm{CeC}$ neurons in slices from fear-conditioned mice may, at least in part, be due to presynaptic changes that affect both components of the EPSCs equally. Alternatively, an enhancement of postsynaptic NMDAR function that preserves NMDA/AMPA ratios at potentiated synapses (see Watt et al., 2004) might also be involved. 


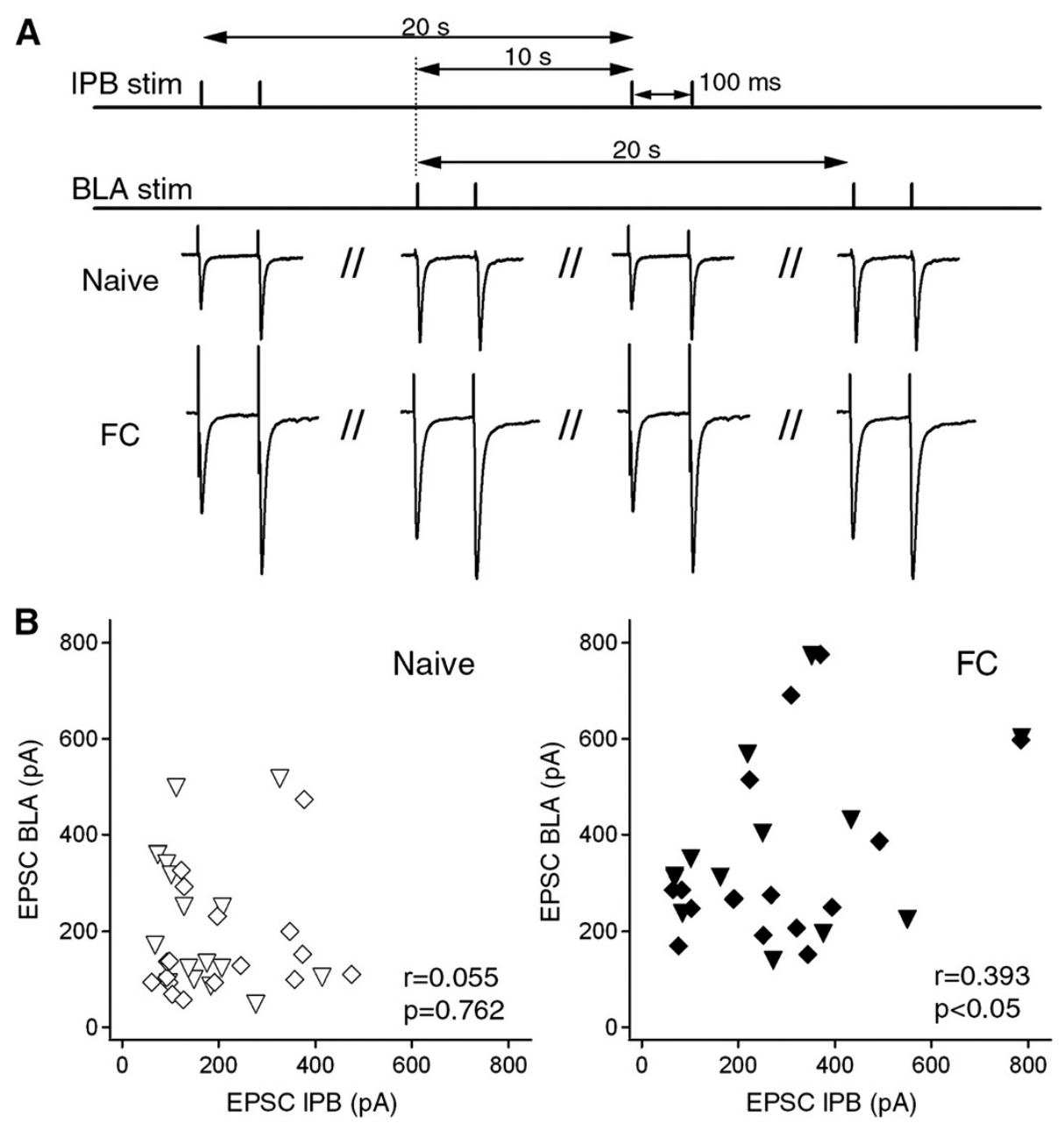

Figure 4 Correlation between IPB-CeC and BLA-CeC EPSC amplitudes. A, Experimental design for alternative stimulation of IPB and BLA pathways. B, Correlation between EPSC amplitudes of IPB-CeC (abscissa) and BLA-CeC (ordinates) synapses in naive mice (left panel, open symbols; $n=33$ ) and fear-conditioned mice (right panel, filled symbols; $n=29$ ). Each symbol represents data from the same set of neurons of the two pathways; the stimulation intensity of the IPB and BLA pathways was identical for these data. Different symbols represent recordings evoked by $400 \mu \mathrm{A}$ (diamonds) and $500 \mu \mathrm{A}$ (inverted triangles) stimulus intensities.

Although NMDA/AMPA ratios were not changed following fear conditioning, we did observe alterations in the kinetics of NMDA-mediated EPSCs in slices from fearconditioned mice. The decay in the EPSCs measured at a membrane potential of $+40 \mathrm{mV}$ in the presence of CNQX was best fitted with double exponential time constants (Figure 6A1, B1) as previously reported [30], with $\tau_{\text {fast }}=$ $58.4 \pm 14.1 \mathrm{msec}$ and $\tau_{\text {slow }}=223.4 \pm 28.2 \mathrm{msec}$ in naive mice at $1 \mathrm{~PB}-\mathrm{CeC}$ synapses $(\mathrm{n}=16)$, and $\mathrm{\tau}_{\text {fast }}=61.6 \pm 6.6$ msec and $\tau_{\text {slow }}=305.5 \pm 28.0$ msec in FC mice at lPB-CeC synapses ( $\mathrm{n}=21$; Figure $6 \mathrm{~A} 2$ and A3). The $\mathrm{\tau}_{\text {slow }}$ was significantly larger $(p<0.05)$ in IPB-CeC synapses in FC mice than in naive mice, suggesting that different synaptic NMDA receptor subunits and/or phosphorylation states might play a role in fear learning. We found no significant differences in the kinetics of the NMDA receptor-mediated EPSC at BLA$\mathrm{CeC}$ synapses between $\mathrm{FC}$ and naive mice, with $\tau_{\text {fast }}=34.6$ $\pm 4.2 \mathrm{msec}$ and $\tau_{\text {slow }}=302.4 \pm 43.3 \mathrm{msec}$ in naive mice $(\mathrm{n}=$ $12)$, and $\tau_{\text {fast }}=41.1 \pm 8.9 \mathrm{msec}$ and $\tau_{\text {slow }}=242.2 \pm 28.4 \mathrm{msec}$ in FC mice $(n=10$; Figure 6B2 and B3). The larger decay time constant of the slow decay component may reflect a contribution of GluN2B subunits [30-32]. Further study is needed to clarify the nature of any NMDA receptor component change following fear learning.

\section{Quantal postsynaptic responses underlying the potentiation of IPB-CeC and BLA-CeC synapses}

To better define the potential presynaptic and postsynaptic contributions to fear conditioning-induced potentiation at synapses onto $\mathrm{CeC}$ neurons, we investigated the quantal amplitude of synaptic inputs by analyzing asynchronous events evoked in the presence of $5 \mathrm{mM}$ strontium, which replaced the extracellular calcium [33]. These asynchronous EPSCs (aEPSCs) were separately 

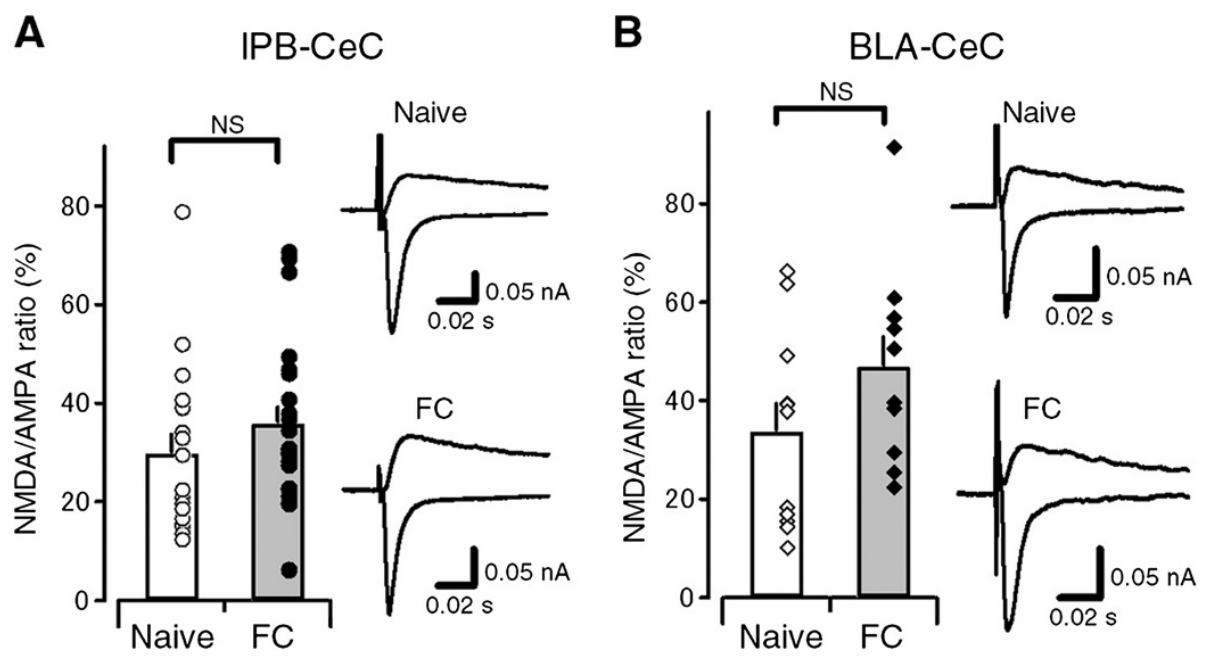

Figure 5 NMDA/AMPA ratio in IPB-CeC and BLA-CeC synapses. A, The NMDA/AMPA ratio in naive (open bar; $n=17$ ) and fear-conditioned (filled bar; $\mathrm{n}=22$ ) mice at IPB-CeC synapses. Circles indicate the individual ratio for each neuron. Sample traces of NMDA current (upper trace) and AMPA current (lower trace) are superimposed for naive (top) and FC (bottom) mice. The average of 15 consecutive waves (5 min) taken $20-$ $25 \mathrm{~min}$ after CNQX application, followed by changing holding potential to $\mathrm{Vh}=+40 \mathrm{mV}$, and those taken $5 \mathrm{~min}$ before the application of CNQX at a holding potential of $\mathrm{Vh}=-60 \mathrm{mV}$ are superimposed. $\mathbf{B}$, The NMDA/AMPA ratio in naive (open bar; $\mathrm{n}=11$ ) and fear-conditioned (filled bar; $\mathrm{n}=20$ ) mice in BLA-CeC synapses. Diamonds indicate individual ratio for each neuron. Sample traces of NMDA current (upper trace) and AMPA current (lower trace) are superimposed for naive (top) and FC (bottom) mice. The average of 15 consecutive waves (5 min) taken 20-25 min after CNQX application, followed by changing holding potential to $\mathrm{Vh}=+40 \mathrm{mV}$, and those taken $5 \mathrm{~min}$ before the application of CNQX at a holding potential of $\mathrm{Vh}=-60 \mathrm{mV}$ are superimposed.

analyzed for the $\mathrm{PBB}$ and BLA pathways. Figure 7 A1 and $\mathrm{B} 1$ show representative traces, in which events with larger amplitude were recorded from FC mice compared with naive mice. The distribution of the aEPSC amplitude histogram was skewed towards larger amplitude in neurons from FC mice, compared with naive mice, at IPB-CeC synapses (308 events in 5 cells from 2 FC mice, and 416 events in 6 cells from 3 naive mice, $p<0.0001$, KS test; Figure 7A2) as well as at BLA-CeC synapses (300 events in 5 cells from 2 FC mice, and 464 events in 6 cells from 3 naive mice, $p<0.004$, KS test; Figure 7B2). These results indicate that quantal responses with larger amplitude emerged in both $\mathrm{IPB}-\mathrm{CeC}$ and $\mathrm{BLA}-\mathrm{CeC}$ synapses after fear learning, suggesting an important role of enhanced postsynaptic AMPAR function in the potentiation of these two pathways.

\section{Nociceptive thresholds in fear-conditioned mice}

The $\mathrm{IPB}-\mathrm{CeC}$ synapses are also known to express nociception-induced plasticity $[14,25,34,35]$, which can modulate nocifensive behaviors by modifying nociceptive threshold, probably via descending regulatory pathways [24]. In this study, we employed a rather stronger protocol for fear conditioning to increase the likelihood of activating more $\mathrm{CeC}$ neurons. This might have developed a nociception-induced plasticity in nociceptive threshold. To examine this possibility, we evaluated changes in the nociceptive threshold by estimating the paw withdrawal threshold and the thermal tail-flick response. We found no significant changes in the nociceptive threshold against mechanical (Figure 8A) or thermal (Figure 8B) stimulation in the fear-conditioned mice.

\section{Discussion}

It is widely accepted that LA pyramidal neurons play a significant role in the association of CS and US during fear memory formation [2,36-38]. However, accumulating data suggest that other brain regions including the CeA $[3,4,39]$, also have an important role in the acquisition of fear memory. Our results showing that $\mathrm{PB}$ and BLA synapses onto $\mathrm{CeC}$ neurons are potentiated following fear learning indicate that the $\mathrm{CeC}$ likely represents another important site for the association of CS and US signals in fear learning. Thus, during the sequential flow of information from the LA to the BLA to the $\mathrm{CeC} / \mathrm{CeL}$ to the CeM, polymodal CS information may be integrated and associated with US-related information at each step in this pathway. This suggests that, in addition to the LA, there may be multiple sites in this serial processing circuit, such as in the $\mathrm{CeC}$, where CS-US associations can occur and that such a multi-site integration system may allow robust and modality-specific regulation of fear learning.

\section{Molecular mechanisms underlying synaptic plasticity}

The decreased PPR at BLA-CeC and IPB-CeC synapses in cells from fear-conditioned mice indicates that increases in presynaptic vesicle release probability contribute to the 
A1

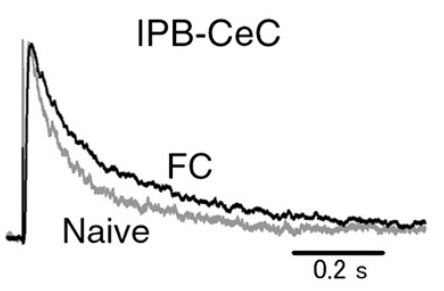

A2

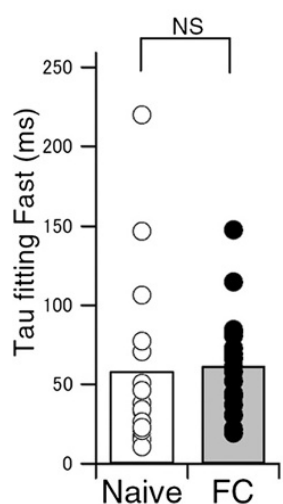

(16) (21)
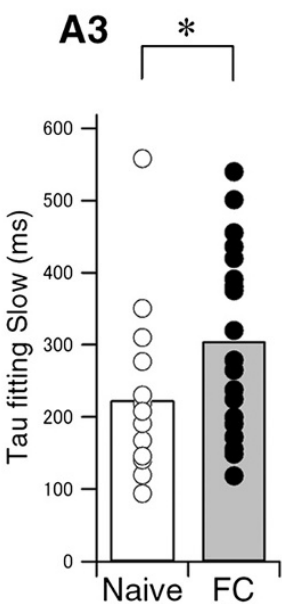

(16) (21)
B1

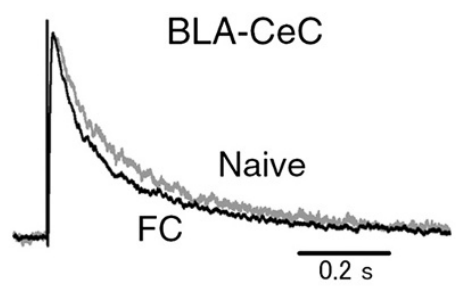

B2

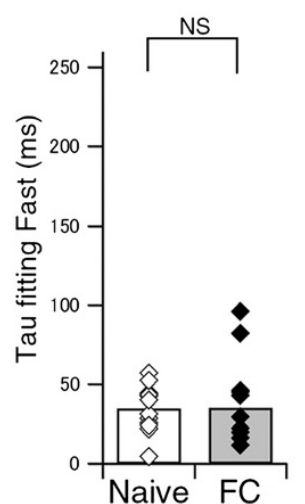

(12) (10)

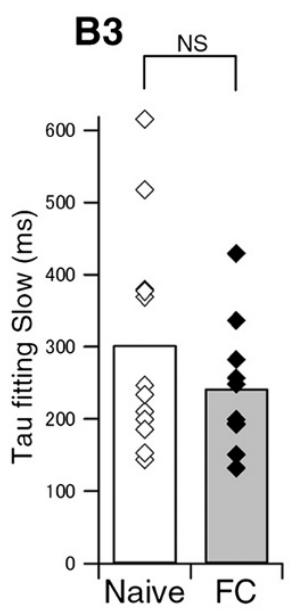

(12) (10)

Figure 6 Kinetics of NMDA receptor-mediated EPSCs in IPB-CeC and BLA-CeC pathways. A1, Representative traces of scaled NMDA receptor-mediated EPSCs recorded at $+40 \mathrm{mV}$ in the presence of CNQX from naive (gray line) and FC (solid line) mice at IPB-CeC synapses. The averaged fast (A2) and slow (A3) decay time constants of NMDA receptor-mediated EPSCS at IPB-CeC synapses from naive (open bar) and FC (filled bar) mice. Individual values for all the cells are superimposed on the bars. B1, Representative traces of scaled NMDA receptor-mediated EPSCs recorded at $+40 \mathrm{mV}$ in the presence of CNQX from naive (gray line) and FC (solid line) mice at BLA-CeC synapses. Averaged fast (B2) and slow (B3) decay time constants of NMDA receptor-mediated EPSCS at BLA-CeC synapses from naive (open bar) and FC (filled bar) mice. Note that at IPB-CeC synapses, the slow decay time constant was significantly increased in FC mice compared with naive mice.

potentiation of these synapses following fear conditioning. We also found, however, that the distribution of aEPSC amplitude was significantly skewed towards larger amplitudes in FC mice compared with naive animals (Figure 7). This indicates that the number and/or activity of postsynaptic AMPA receptor is also enhanced following fear learning. Thus, both presynaptic and postsynaptic changes appear to contribute substantially to the strengthening of these synapses in fear conditioning. Consistent with this notion, the kinetics of NMDA receptor-mediated EPSCs were significantly altered in the $\mathrm{IPB}-\mathrm{CeC}$ pathway (Figure 6A3), suggesting that a change in subunit composition and/or other modifications may have occurred at least in the IPB-CeC synapses. Taken together, the present findings demonstrate that the synaptic potentiation is mediated by an increase in vesicular release probability together with postsynaptic AMPA receptor modulation, which might also accompany the potentiation of NMDA receptors. These results are of particular interest because BLA and IPB inputs form synapses onto different dendritic sites in $\mathrm{CeC}$ neuron; the BLA inputs form synapses onto the dendritic spines, while the IPB inputs do so on the dendritic shafts [27]. The correlation between BLA-
$\mathrm{CeC}$ and $\mathrm{PBB}-\mathrm{CeC}$ synaptic potentiation suggests some heterosynaptic interaction between these two distinct pathways. The most plausible mechanisms might include postsynaptic spine-to-shaft or shaft-to-spine interactions. For example, synaptic potentiation in the BLA-CeC pathway might be integrated and associated further at the $\mathrm{CeC}$ through the $\mathrm{PBB}-\mathrm{CeC}$ pathway, resulting in heterosynaptic potentiation of the $\mathrm{IPB}-\mathrm{CeC}$ synapses. Alternatively, $\mathrm{PBB}-$ $\mathrm{CeC}$ synaptic potentiation by nociceptive associative learning would intensify its instructive function in heterosynaptic plasticity, possibly leading to an additional potentiation of BLA-CeC synapses. The non-significant BLA-CeC potentiation following fear conditioning without retrieval (i.e., FC alone group) may suggest such IPB to BLA interaction in plasticity regulation. One of the plausible interpretations is that a slective activation of BLA-CeC synaptic transmission by thalamocortical inputs, such as that seen in retrievals, would be one of the factors that help maintaining the potentiation.

\section{BLA-CeC synaptic potentiation following fear learning}

In the present study, we identified BLA-CeC potentiation following fear learning. In contrast, a previous 


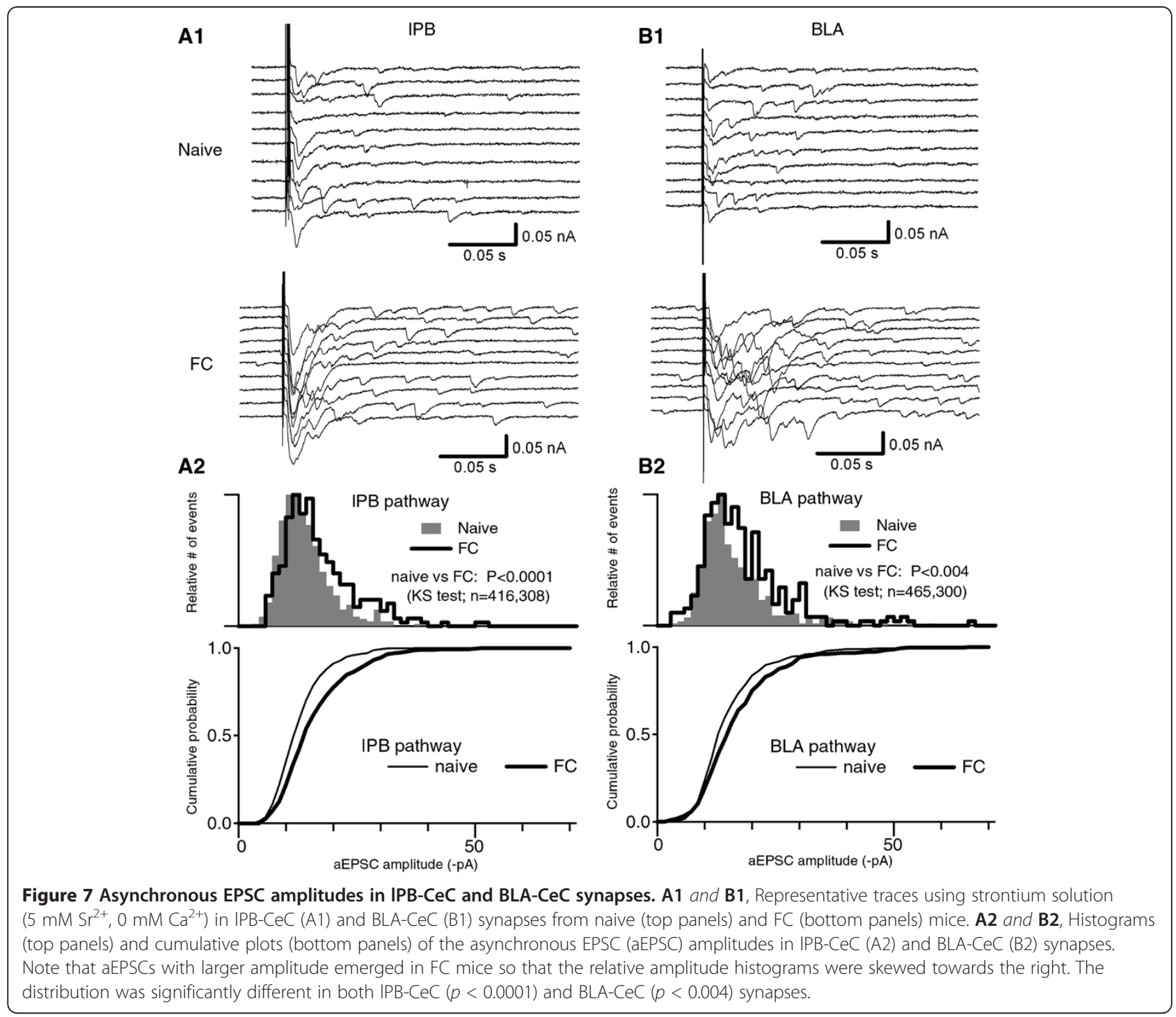

study reported that BLA-CeL synapses were not potentiated after fear learning in rats [6]. Differences in experimental protocols might account for this discrepancy. For example, Amano et al. examined synaptic transmission $48 \mathrm{~h}$ after conditioning, while we examined synaptic transmission $24 \mathrm{~h}$ after conditioning. Thus, one possibility is that the potentiation of BLA synaptic inputs onto neurons in the central nucleus is transient and decays with a slow time course post-conditioning. Also, animals were conditioned using 4-pairings in the experiments of Amano et al. while 9-pairings were employed in our experiments. Thus, another possibility is that extended training may enhance the potentiation or the ability to detect potentiation of BLA inputs simply by recruiting a larger population of $\mathrm{CeC}$ neurons during conditioning. Finally, Amano et al. recorded from the $\mathrm{CeL}$, which may include both the $\mathrm{CeL}$ and $\mathrm{CeC}$ judged by our criterion, while our recordings focused mainly on neurons in the $\mathrm{CeC}$ region. Thus, fear conditioning may have different effects on BLA synaptic inputs onto neurons in distinct subdivisions of the central nucleus. In support of this notion, previous detailed analysis revealed that $\mathrm{CeC}$ and $\mathrm{CeL}$ neurons target different areas within the amygdala [5]. Furthermore, projection of IPBarising fibers to CeA shows a latero-medial gradient [27], which is accompanied with distinct morphological properties in the presynaptic terminals [16]. It is interesting, however, that Amano et al. (2010) reported that BLA-CeL synapses are potentiated by unpaired presentations of the US and CS, suggesting that plasticity at these synapses may be involved in contextual fear conditioning. It would be intriguing to pursue dissociation between BLA-CeC and IPB$\mathrm{CeC}$ synaptic potentiation in a future study.

While the increased release probability after fear conditioning in this study is reminiscent of NMDA receptorindependent presynaptic LTP following tetanic stimulation at IPB-CeL synapses [26], the IPB-CeC potentiation observed in 


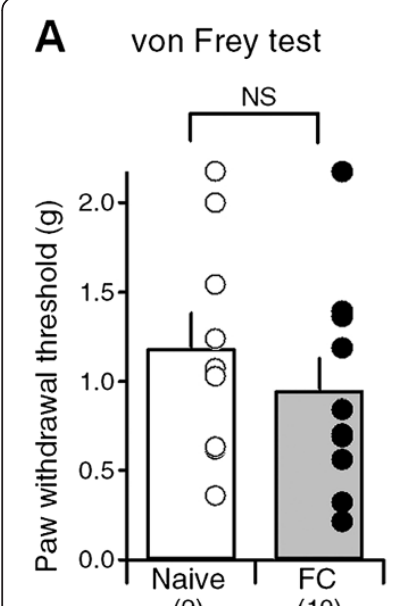

(9)

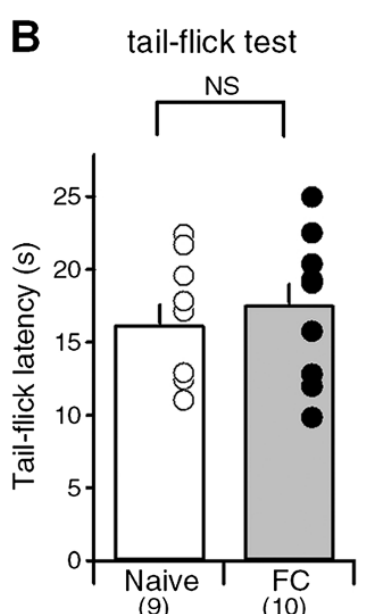

(9) established that the fear memory recall with cues and/or contexts in the fear-conditioned animals attenuate nociceptive behaviors, which is termed as conditioned fear analgesia. It is postulated that shared CNS regions including the amygdala and periaqueductal grey underlie such interaction [40-42]. In contrast, in the present study, the nociceptive threshold was measured in the absence of fear cues to measure the nociceptive threshold at the spinal level in isolation. Therefore, our data simply demonstrate that, at least at $24 \mathrm{~h}$ after FC, the enhanced connectivity of spino-parabrachio-amygdaloid pathway is not accompanied by enhanced spinal nociceptive reflex (Figure 8A, 8B). It is therefore an interesting future subject whether such synaptic enhancement after fear learning would result in development of enhanced paininduced behavior and/or lowered pain threshold in later phases. The results of such study would provide etiological basis for the significantly higher incidents of PTSD in the chronic pain patients [43].

Pain is an emotional state whereby noxious stimuli detected and processed by nociceptors are integrated and associated with negative affective factors. The $\mathrm{CeC}$ plays a pivotal role in associating this emotional component with nociceptive signals, by integrating direct nociceptive signals from the IPB with highly processed polymodal signals from the BLA. Thus, one possibility is that $\mathrm{PPB}-\mathrm{CeC}$ synaptic potentiation is not the underlying mechanism of fear learning per se, but rather a consequence of fear learning; that is, this potentiation provides a trace of noxious experience, thereby allowing animals to more readily associate BLA signals with concurrent IPB signals that convey nociceptive/aversive information. Such metaplastic mechanisms might regulate the threshold and/or efficacy of subsequent fear learning [44]. Another possible physiological consequence of the synaptic potentiation of the $\mathrm{IPB}-\mathrm{CeC}$ pathway might be fear generalization, in which CS specificity is compromised so that conditioned fear responses are generalized to tones other than the one paired with US $[45,46]$. It may be useful for future studies to examine the causality between synaptic potentiation and its behavioral consequences using molecular and/or optogenetic approaches to clarify these issues in detail.

The multi-step mode of synaptic plasticity observed in the present study functions in an organized manner, allowing highly processed multimodal signals in the LA to be integrated and further associated with negative affective information in the $\mathrm{CeC}$. A report appearing after the submission of this paper indicated a synaptic potentiation of LA input onto somatostatin-positive cells in CeL following fear conditioning in mice [47]. This highly convincing work is also an example supportive of the notion that fear-related associative memory is borne at multiple steps in the amygdaloid information traffic

\section{Physiological consequences of synaptic potentiation at the $\mathrm{CeC}$}

A large number of literatures suggest relationship between the fear learning and the pain regulation. It is well 
among LA, BLA, CeC, CeL and CeM. As each of these structures receives distinct neuronal inputs from diverse origins and also is under strong influence of distinct chemical modulators such as monoamines and neuropeptides, it is conceivable that such multi-step regulation system would allow more robust optimization of the behavioral program in response to aversive information.

\section{Conclusions}

In summary, the present study demonstrates synaptic potentiation of both $\mathrm{PB}-\mathrm{CeC}$ and $\mathrm{BLA}-\mathrm{CeC}$ pathways following fear learning in an associative manner, which is mediated by both presynaptic and postsynaptic mechanisms. These results suggest that the $\mathrm{CeC}$ may provide another locus of CS-US association, in addition to the $\mathrm{LA}$, in fear memory formation.

\section{Methods}

The manipulation of the animals was approved by the Institutional Committee for the Care and Use of Experimental Animals of The Jikei University School of Medicine (Approval No. 21-061C5). All experiments were conformed to the Guidelines for Proper Conduct of Animal Experiments of the Science Council of Japan (2006) and to the guidelines of the International Association for the Study of Pain (Zimmermann 1983).

\section{Fear conditioning}

Male C57BL/6 J mice (5-6 weeks old) (CLEA Japan Inc., Tokyo, Japan) were group-housed under a 12-h light/ dark cycle, and provided with food and water ad libitum. Animals were habituated to handling for more than 7 days before being divided into five groups (Figure 1A); naive, fear-conditioned (FC), FC alone, CS alone and unpaired groups. All the conditioning procedures were conducted in a conditioning chamber $(170 \mathrm{~mm}$ width $\times$ $100 \mathrm{~mm}$ depth $\times 100 \mathrm{~mm}$ height) surrounded by a sound-attenuating chamber (CL-M3, O'Hara \& Co., Ltd., Tokyo, Japan). For the FC group, mice received nine presentations of tone CS $(10 \mathrm{kHz}, 65 \mathrm{~dB}, 20 \mathrm{~s})$, each terminating with a foot shock US $(0.6 \mathrm{~mA}, 2 \mathrm{~s})$, presented in a conditioning chamber ( $200 \mathrm{Lux}, 50 \mathrm{~dB}$ background white noise). The first CS was delivered $120 \mathrm{~s}$ after the animal was placed in the chamber, and inter-trial intervals were pseudo-randomly selected, ranging from 40 to $480 \mathrm{~s}$. A retrieval trial was performed $24 \mathrm{~h}$ later in a novel chamber (with a white acrylic plate wall washed with peppermint-scented soap). The CS presentation began $120 \mathrm{~s}$ after the mice were placed in the chamber, and lasted for $120 \mathrm{~s}$ (50 Lux, $60 \mathrm{~dB}$ background white noise). Mice in the FC alone group received exactly the same fear conditioning as FC mice, but were not subjected to the retrieval tests. Mice in the CS alone group were treated similarly to the FC group, with the exception that they received only tone CS, with no accompanying US, during the conditioning. For the unpaired group, the mice received nine US immediately after being placed into the conditioning chamber with 2$\mathrm{s}$ intervals, followed by nine CS presentations with 5-s intervals. Freezing behavior was measured using a digital camera connected to a computer running Time FZ1 (O'Hara \& Co., Ltd), a software package based on NIH Image, which was calibrated for the counting of freezing behavior by C57BL/ 6 mice using scoring performed by two independent human observers prior to the actual experiments. Slice preparation was performed approximately $15 \mathrm{~min}$ after the end of retrieval for the FC, CS alone and unpaired groups, and $24 \mathrm{~h}$ after conditioning for the FC alone group. Mice in the naive group were handling-habituated only followed by slice preparation.

\section{Amygdala slice preparation and patch-clamp recording}

The mice were anesthetized with isoflurane (5\%) and sacrificed. The brain was removed and blocks containing the amygdala were prepared in ice-cold cutting solution containing (in $\mathrm{mM}$ ) $\mathrm{NaCl} 125, \mathrm{KCl} 3, \mathrm{CaCl}_{2} 0.1, \mathrm{MgCl}_{2} 5$, $\mathrm{NaH}_{2} \mathrm{PO}_{4}$ 1.25, D-glucose 10, L-ascorbic acid 0.4 and $\mathrm{NaHCO}_{3} 25$ (pH 7.4) equilibrated with 95\% $\mathrm{O}_{2} / 5 \% \mathrm{CO}_{2}$. Transverse brain slices, $400 \mu \mathrm{m}$ thick, containing the central amygdala were prepared using a vibrating blade slicer (VT1200S, Leica) at $0^{\circ} \mathrm{C}$, transferred to a chamber

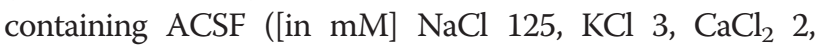
$\mathrm{MgCl}_{2}$ 1.3, $\mathrm{NaH}_{2} \mathrm{PO}_{4}$ 1.25, D-glucose 10, L-ascorbic acid 0.4 and $\mathrm{NaHCO}_{3} 25$ [pH 7.4]) and incubated in an atmosphere of $95 \% \mathrm{O}_{2} / 5 \% \mathrm{CO}_{2}$ at $37^{\circ} \mathrm{C}$ for $30 \mathrm{~min}$, then maintained for several hours in ACSF at room temperature. Neurons in the latero-capsular division of the CeA were visually identified using oblique illumination optics microscopy (BX51WI, Olympus) and a charge-coupled device camera (IR-1000, DageMTI),. Each coronal slice was matched with the corresponding rostrocaudal level of Paxinos and Franklin [8]. Whole-cell recordings were made from brain slices maintained at $30 \pm 2^{\circ} \mathrm{C}$ in a recording chamber continuously perfused with oxygenated ACSF $\left(95 \% \mathrm{O}_{2} / 5 \% \mathrm{CO}_{2}\right)$ at a flow rate of $1.5-2.0 \mathrm{ml} / \mathrm{min}$. The tip resistance of the recording electrodes was 4-9 $M \Omega$, and the recording electrodes were filled with internal solution containing (in mM) Cs-gluconate 122.5, $\mathrm{CsCl} 17.5, \mathrm{NaCl} 8$, HEPES 10, EGTA 0.2, ATP magnesium 2, GTP sodium 0.3 (pH 7.2; osmolarity, 290-310 mOsm).

With custom-designed bipolar parallel stimulation electrodes (TOG211-039a, Unique Medical Co., Ltd., Tokyo, Japan), EPSCs were evoked in $\mathrm{CeC}$ neurons by electrical stimulation of the two afferent synapses to the $\mathrm{CeC}$ : the IPB and BLA pathways under microscopic control (Figure 1C, D) as described previously [25,29]. The IPB-stimulating electrode was placed onto the fibers that run dorsomedial to the CeA and ventral to, but outside 
of, the caudate-putamen. BLA-stimulating electrode was placed in the ventral BLA near the borderline to the CeA $[25,29,46]$. Picrotoxin $(100 \mu \mathrm{M})$ was present in the ACSF to isolate EPSCs. EPSCs were recorded at a holding potential of $-60 \mathrm{mV}$ with a patch-clamp amplifier (MultiClamp 700B, Molecular Devices, Foster City, CA), low-pass filtered at $2 \mathrm{kHz}$ and sampled at $10 \mathrm{kHz}$ at a 16-bit resolution with a PowerLab interface (AD Instruments) and pClamp 10 software (Molecular Devices). The series resistance was constantly monitored, and data were discarded if they varied more than $20 \%$ within an experiment.

To calculate the paired-pulse ratio (PPR) of EPSCs, two pulses with an interstimulus interval of $100 \mathrm{~ms}$ were delivered, except for the cross-pathway PPR experiments in which 50-ms interval was applied. The PPR was calculated as normalized amplitude $\mathrm{EPSC}_{2 \mathrm{nd}} / \mathrm{EPSC}_{1 \mathrm{st}}$.

When NMDA receptor-mediated EPSCs were recorded, $10 \mu \mathrm{M}$ 6-cyano-7-nitroquinoxaline-2,3-dione (CNQX) was bath-applied to block AMPA-type glutamate receptormediated EPSCs and the holding potential was kept at +40 mV. To analyze NMDA receptor-mediated EPSC kinetics, we averaged 15 consecutive EPSCs, and the current decay was fitted using a previously reported doubleexponential equation as follows:

$$
\mathrm{I}_{\mathrm{t}}=\mathrm{I}_{\mathrm{f}} \exp \left(-t / \mathrm{\tau}_{\text {fast }}\right)+\mathrm{I}_{\mathrm{t}} \exp \left(-t / \mathrm{\tau}_{\text {slow }}\right)
$$

To isolate asynchronous EPSCs (aEPSCs), extracellular $\mathrm{Ca}^{2+}(2 \mathrm{mM})$ was replaced with $\mathrm{Sr}^{2+}(5 \mathrm{mM})$ after confirming stable postsynaptic responses evoked by the stimulation of $\mathrm{PBB}-\mathrm{CeC}$ and $\mathrm{BLA}-\mathrm{CeC}$ pathways. The amplitude of aEPSC was evaluated between $20 \mathrm{~ms}$ and $120 \mathrm{~ms}$ poststimulus to exclude synchronously released evoked events. The recordings were obtained for five minutes after confirming the external $\mathrm{Ca}^{2+}$-containing solution was fully replaced by $\mathrm{Sr}^{2+}$-containing solution for more than $15 \mathrm{~min}$.

Cross-pathway PPR experiments were conducted in naive male C57BL/6 J mice (7-8 weeks old) to examine the possible overlap between the fibers stimulated by the IPB-stimulating and BLA-stimulating electrodes. Baseline EPSCs were obtained using a paired-pulse protocol in each pathway (single-pathway PPR; 50-ms inter-pulse interval, $0.05 \mathrm{~Hz}$, stimulation of the two pathways were separated by $10 \mathrm{~s}$ ). Following stable baseline, crosspathway PPR between $\mathrm{IPB}-\mathrm{CeC}$ pathway and BLA-CeC pathway was measured by stimulating $\mathrm{IPB}-\mathrm{CeC}$ pathway $50 \mathrm{~ms}$ after BLA-CeC pathway, or vice versa. Crosspathway PPR is defined as EPSC 2nd BLA of cross-path PPR

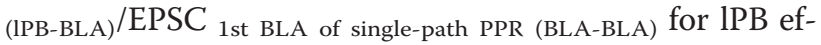
fect on BLA pathway, and EPSC 2nd IPB of cross-path PPR

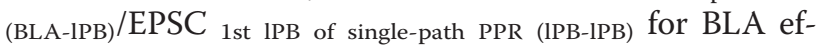
fect on IPB pathway.

\section{Evaluation of nociceptive responses}

The paw withdrawal threshold to mechanical stimuli was evaluated by experienced experimenters, according to a previously reported method [48]. Mechanical stimuli were applied using von Frey filaments of different rigidity $(0.02-2.0 \mathrm{~g})$. Each mouse was placed on a metal mesh floor, and a von Frey filament was applied manually from beneath. The $50 \%$ threshold was estimated using the up-and-down method [49]. The mice were allowed to habituate in the $500-\mathrm{ml}$ glass beaker placed up-side down on the mesh floor at least for 30 min prior to the experiments. Judgment of the paw withdrawal reflex was done by experienced examinators to avoid unnecessary re-examination. The results were compared "on-site" with the estimation table for 50\%-threshold and the test was terminated once the minimum necessary data for estimation was attained. The mechanical threshold was determined as the average of both hindpaw measurements per mouse.

The thermal nociceptive response was evaluated by recording the latency to withdrawal of the tail in response to noxious skin heating. Briefly, the tails of mice were exposed to a focused beam of light from a $50-\mathrm{W}$ projection bulb. The beam intensity was set to produce a temperature of $75^{\circ} \mathrm{C}$ using a tail-flick analgesia meter MK-330B (Muromachi Kikai Co., Ltd., Tokyo, Japan). In the absence of a response within a predetermined maximum latency (30 s), the trial was terminated to prevent tissue damage.

\section{Data and statistical analysis}

The recorded membrane current was analyzed off-line using an Igor Pro 5 (WaveMetrics, OR, USA) using macros written by one of the authors (F.K.). Peak amplitude was measured on the basis of the averaged waveform of evoked EPSCs (five consecutive trials). Values are expressed as mean \pm standard error of the mean (SEM). Statistical analysis consisted of analysis of variance (ANOVA) followed by post hoc Dunnett's test, Student's $t$-test, Kolmogorov-Smirnov (KS) test or MannWhitney $U$ test. Differences with a $p$-value less than 0.05 were considered significant.

\section{Abbreviations \\ CeA: Central nucleus of the amygdala; CeC: The capsular division of CeA; IPB: External part of the lateral parabrachial nucleus; BLA: Basolateral nucleus of the amygdala; EPSC: Excitatory postsynaptic current; NMDA: N-methyl-D- aspartate; AMPA: a-amino-3-hydroxy-5-methyl-4-isoxazolepropionic acid.}

\section{Competing interests}

The authors declare no conflict of interest.

\section{Authors' contributions}

The research was designed by AMW and FK and performed in the laboratory of FK. The experiments were performed by AMW, TO, and MN. The data were analyzed by AMW, TO, MN, and FK with assistance of YT and MS. The manuscript was written by AMW and FK All authors have read and approved the final version of the manuscript. 


\section{Acknowledgments}

This work was supported by the Japan Science and Technology Agency, PRESTO (to AMW), Grants-in-Aid for Scientific Research from the Japan Society for the Promotion of Science and the Ministry of Education, Science, Sports, Culture and Technology of Japan (to AMW and FK), and "Bioinformatics for brain sciences" carried out under the Strategic Research Program for Brain Sciences (to FK). We thank all members of the Kato laboratory for their support and discussion. We are grateful for assistance from N Numata, K Ishihara and T Matsuo-Tarumi. We thank Dr. TJ O'Dell for helpful comments on the earlier version of the manuscript.

\section{Author details}

'Department of Neuroscience, Jikei University School of Medicine, Tokyo 105-8461, Japan. ²Precursory Research for Embryonic Science and Technology (PRESTO), Japan Science and Technology Agency, Kawaguchi, Saitama 332-0012, Japan. ${ }^{3}$ Department of Pathophysiology and Therapeutics, School of Pharmacy and Pharmaceutical Sciences, Hoshi University, Tokyo 142-8501, Japan. ${ }^{4}$ Department of Anesthetics, Jikei University School of Medicine, Tokyo 105-8461, Japan. ${ }^{5}$ Nagoya University Graduate School of Medicine, Nagoya 466-8550, Japan.

Received: 25 January 2013 Accepted: 26 February 2013

Published: 1 March 2013

\section{References}

1. Davis M, Whalen PJ: The amygdala: vigilance and emotion. Mol Psychiatry 2001, 6(1):13-34

2. LeDoux JE: Emotion circuits in the brain. Annu Rev Neurosci 2000, 23:155-184.

3. Wilensky AE, Schafe GE, Kristensen MP, LeDoux JE: Rethinking the fear circuit: the central nucleus of the amygdala is required for the acquisition, consolidation, and expression of Pavlovian fear conditioning. J Neurosci 2006, 26(48):12387-12396.

4. Zimmerman JM, Rabinak CA, McLachlan IG, Maren S: The central nucleus of the amygdala is essential for acquiring and expressing conditional fear after overtraining. Learn Mem 2007, 14(9):634-644.

5. Busti D, Geracitano R, Whittle N, Dalezios Y, Manko M, Kaufmann W, Satzler K, Singewald N, Capogna M, Ferraguti F: Different fear states engage distinct networks within the intercalated cell clusters of the amygdala. J Neurosci 2011, 31(13):5131-5144.

6. Amano T, Unal CT, Pare D: Synaptic correlates of fear extinction in the amygdala. Nat Neurosci 2010, 13(4):489-494

7. Ehrlich I, Humeau Y, Grenier F, Ciocchi S, Herry C, Luthi A: Amygdala inhibitory circuits and the control of fear memory. Neuron 2009, 62(6):757-771.

8. Paxinos GF, Franklin KBJ: The mouse brain in stereotaxic coordinates. compact secondth edition. San Diego: Academic Press; 2004

9. Ciocchi S, Herry C, Grenier F, Wolff SB, Letzkus JJ, Vlachos I, Ehrlich I, Sprengel R, Deisseroth K, Stadler MB, et al: Encoding of conditioned fear in central amygdala inhibitory circuits. Nature 2010, 468(7321):277-282.

10. Haubensak W, Kunwar PS, Cai H, Ciocchi S, Wall NR, Ponnusamy R, Biag J, Dong HW, Deisseroth K, Callaway EM, et al: Genetic dissection of an amygdala microcircuit that gates conditioned fear. Nature 2010 468(7321):270-276

11. Duvarci S, Popa D, Pare D: Central amygdala activity during fear conditioning. J Neurosci 2011, 31(1):289-294.

12. Bernard JF, Alden M, Besson JM: The organization of the efferent projections from the pontine parabrachial area to the amygdaloid complex: a Phaseolus vulgaris leucoagglutinin (PHA-L) study in the rat. J Comp Neurol 1993, 329(2):201-229.

13. Bernard JF, Bandler R: Parallel circuits for emotional coping behaviour: new pieces in the puzzle. J Comp Neurol 1998, 401(4):429-436.

14. Neugebauer V, Li W: Differential sensitization of amygdala neurons to afferent inputs in a model of arthritic pain. J Neurophysiol 2003, 89(2):716-727.

15. Todd AJ: Neuronal circuitry for pain processing in the dorsal horn. Nat Rev Neurosci 2010, 11(12):823-836.

16. Sarhan M, Freund-Mercier M-J, Veinante P: Branching patterns of parabrachial neurons projecting to the central extended amgydala: Single axonal reconstructions. J Comp Neurol 2005, 491(4):418-442.

17. Fanselow MS, Gale GD: The amygdala, fear, and memory. Ann N Y Acad Sci 2003, 985:125-134.
18. Sah P, Faber ES, Lopez De Armentia M, Power J: The amygdaloid complex: anatomy and physiology. Physiol Rev 2003, 83(3):803-834.

19. Pare D: New vistas on amygdala networks in conditioned fear. J Neurophysiol 2004, 92(1):1-9.

20. Phelps EA, LeDoux JE: Contributions of the amygdala to emotion processing: from animal models to human behavior. Neuron 2005 48(2):175-187.

21. Shi C, Davis M: Pain pathways involved in fear conditioning measured with fear-potentiated startle: lesion studies. J Neurosci 1999, 19(1):420-430.

22. Cheng SJ, Chen CC, Yang HW, Chang YT, Bai SW, Yen CT, Min MY: Role of extracellular signal-regulated kinase in synaptic transmission and plasticity of a nociceptive input on capsular central amygdaloid neurons in normal and acid-induced muscle pain mice. J Neurosci 2011, 31(6):2258-2270.

23. Neugebauer $\mathrm{V}$, Li W: Processing of nociceptive mechanical and thermal information in central amygdala neurons with knee-joint input. J Neurophysiol 2002, 87(1):103-112.

24. Carrasquillo Y, Gereau RW: Activation of the extracellular signal-regulated kinase in the amygdala modulates pain perception. J Neurosci 2007 27(7):1543-1551.

25. Ikeda $R$, Takahashi $Y$, Inoue $K$, Kato F: NMDA receptor-independent synaptic plasticity in the central amygdala in the rat model of neuropathic pain. Pain 2007, 127(1-2):161-172.

26. Lopez de Armentia M, Sah P: Bidirectional synaptic plasticity at nociceptive afferents in the rat central amygdala. J Physio/ 2007, 581(Pt 3):961-970

27. Dong Y-L, Fukazawa Y, Wang W, Kamasawa N, Shigemoto R: Differential postsynaptic compartments in the laterocapsular division of the central nucleus of amygdala for afferents from the parabrachial nucleus and the basolateral nucleus in the rat. J Comp Neurol 2010, 518(23):4771-4791.

28. Xu-Friedman MA, Regehr WG: Structural contributions to short-term synaptic plasticity. Physiol Rev 2004, 84(1):69-85.

29. Neugebauer V, Li W, Bird GC, Bhave G, Gereau RW: Synaptic plasticity in the amygdala in a model of arthritic pain: differential roles of metabotropic glutamate receptors 1 and 5. J Neurosci 2003, 23(1):52-63.

30. Lopez de Armentia M, Sah P: Development and subunit composition of synaptic NMDA receptors in the amygdala: NR2B synapses in the adult central amygdala. J Neurosci 2003, 23(17):6876-6883.

31. Vicini S, Wang JF, Li JH, Zhu WJ, Wang YH, Luo JH, Wolfe BB, Grayson DR: Functional and pharmacological differences between recombinant $\mathrm{N}$ methyl-D-aspartate receptors. J Neurophysiol 1998, 79(2):555-566.

32. Tovar KR, Westbrook GL: The incorporation of NMDA receptors with a distinct subunit composition at nascent hippocampal synapses in vitro. J Neurosci 1999, 19(10):4180-4188.

33. Goda Y, Stevens CF: Two components of transmitter release at a central synapse. Proc Natl Acad Sci USA 1994, 91(26):12942-12946.

34. Han JS, Neugebauer V: Synaptic plasticity in the amygdala in a visceral pain model in rats. Neurosci Lett 2004, 361(1-3):254-257.

35. Bird GC, Lash LL, Han JS, Zou X, Willis WD, Neugebauer V: Protein kinase A-dependent enhanced NMDA receptor function in pain-related synaptic plasticity in rat amygdala neurones. J Physiol 2005, 564(Pt 3):907-921.

36. Tsvetkov E, Carlezon WA, Benes FM, Kandel ER, Bolshakov VY: Fear conditioning occludes LTP-induced presynaptic enhancement of synaptic transmission in the cortical pathway to the lateral amygdala. Neuron 2002, 34(2):289-300.

37. Maren S, Quirk GJ: Neuronal signalling of fear memory. Nat Rev Neurosci 2004, 5(11):844-852.

38. Rumpel S, LeDoux J, Zador A, Malinow R: Postsynaptic receptor trafficking underlying a form of associative learning. Science 2005, 308(5718):83-88.

39. Johansen JP, Tarpley JW, LeDoux JE, Blair HT: Neural substrates for expectation-modulated fear learning in the amygdala and periaqueductal gray. Nat Neurosci 2010, 13(8):979-986.

40. Fanselow MS, Helmstetter FJ: Conditional analgesia, defensive freezing, and benzodiazepines. Behav Neurosci 1988, 102(2):233-243.

41. Helmstetter FJ, Bellgowan PS: Lesions of the amygdala block conditional hypoalgesia on the tail flick test. Brain Res 1993, 612(1-2):253-257.

42. Rea K, Roche M, Finn DP: Modulation of conditioned fear, fearconditioned analgesia, and brain regional C-Fos expression following administration of muscimol into the Rat basolateral amygdala. J Pain 2011, 12(6):712-721. 
43. McWilliams LA, Cox BJ, Enns MW: Mood and anxiety disorders associated with chronic pain: an examination in a nationally representative sample. Pain 2003, 106(1-2):127-133.

44. Parsons $\mathrm{RG}$, Davis $\mathrm{M}$ : A metaplasticity-like mechanism supports the selection of fear memories: role of protein kinase a in the amygdala. J Neurosci 2012, 32(23):7843-7851.

45. Armony JL, Servan-Schreiber D, Romanski LM, Cohen JD, LeDoux JE: Stimulus generalization of fear responses: effects of auditory cortex lesions in a computational model and in rats. Cereb Cortex 1997, 7(2):157-165.

46. Shaban H, Humeau Y, Herry C, Cassasus G, Shigemoto R, Ciocchi S, Barbieri S, van der Putten H, Kaupmann K, Bettler B, et al: Generalization of amygdala LTP and conditioned fear in the absence of presynaptic inhibition. Nat Neurosci 2006, 9(8):1028-1035.

47. Li H, Penzo MA, Taniguchi H, Kopec CD, Huang ZJ, Li B: Experiencedependent modification of a central amygdala fear circuit. Nat Neurosci 2013, 16(3):332-339

48. Tsuda M, Shigemoto-Mogami Y, Koizumi S, Mizokoshi A, Kohsaka S, Salter MW, Inoue K: P2X4 receptors induced in spinal microglia gate tactile allodynia after nerve injury. Nature 2003, 424(6950):778-783.

49. Chaplan SR, Bach FW, Pogrel JW, Chung JM, Yaksh TL: Quantitative assessment of tactile allodynia in the rat paw. J Neurosci Methods 1994, 53(1):55-63.

doi:10.1186/1756-6606-6-11

Cite this article as: Watabe et al.: Synaptic potentiation in the

nociceptive amygdala following fear learning in mice. Molecular Brain 2013 6:11.

\section{Submit your next manuscript to BioMed Central and take full advantage of:}

- Convenient online submission

- Thorough peer review

- No space constraints or color figure charges

- Immediate publication on acceptance

- Inclusion in PubMed, CAS, Scopus and Google Scholar

- Research which is freely available for redistribution 